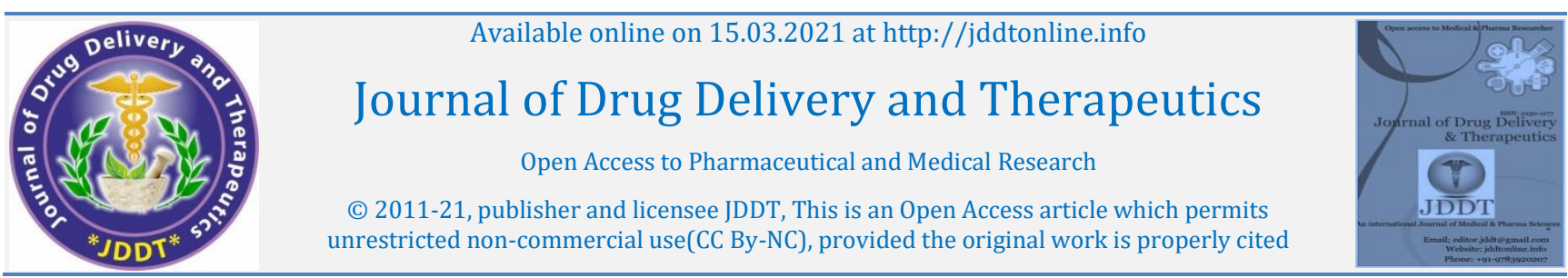

(C) 2011-21, publisher and licensee JDDT, This is an Open Access article which permits

Open Access Full Text Article

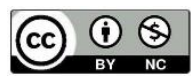

Research Article

\title{
Modification of natural hydrocolloid as disintegrant in aceclofenac tablet formulation
}

\author{
Vandana Gupta*(iD, Ashish Manigauha (D) \\ Mittal Institute of Pharmacy, Opposite Bhopal Memorial Hospital \& Research Centre, Ayodhya Bypass Road, Navi Bagh, Karond, Bhopal-462038,
} M.P., India

Article Info:

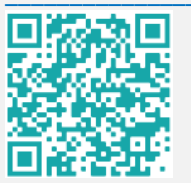

\section{Article History:}

Received 18 Jan 2021;

Review Completed 21 Feb 2021

Accepted 28 Feb 2021;

Available online 15 March 2021

\section{Cite this article as:}

Gupta V, Manigauha A, Modification of natural hydrocolloid as disintegrant in aceclofenac tablet formulation, Journal of Drug Delivery and Therapeutics. 2021; 11(2):42-50

DOI: http://dx.doi.org/10.22270/jddt.v11i2.4586

\section{*Address for Correspondence:}

Vandana Gupta, Mittal Institute of Pharmacy, Opposite Bhopal Memorial Hospital \& Research Centre, Ayodhya Bypass Road, Navi Bagh, Karond, Bhopal-462038, M.P., India. Email: vandanargpv@gmail.com Scopus ID: https://www.scopus.com/authid/detail.uri?authorId=3 6850112900 ORCID ID: https://orcid.org/0000-00022543-5911

\section{Abstract}

The purpose of present exploration was to modify kappa (k)-Carrageenan, by crosslinking, and assessed it as a tablet disintegrant to strengthen the solubility of the drug (aceclofenac) in tablet formulation. Modified k-Carrageenan was synthesized by reacting it with epichlorhydrin at heterogenous conditions. The swelling action of the product was investigated in order to optimize reaction circumstances for chemical crosslinking. Best modified k-Carrageenan procured by optimizing the reaction conditions and it was characterized for swelling index, particle size distribution, solubility, viscosity, gel strength and Fourier transform infrared spectroscopy (FTIR). Influence of modified kCarrageenan on dissolution profile of therapeutic was also investigated along with other evaluation parameters. Modified k-Carrageenan exhibiting significant swelling index which is comparable to that of superdisintegrants. On comparative investigation as a tablet disintegrant by preparing anhydrous dicalcium phosphate tablet, modified kCarrageenan showed disintegration time less than 20 seconds. Dissolution of aceclofenac (Class II) tablet formulaion utilizing modified k-Carrageenan was comparable with commercially available superdisintegrants. Faster dissolution of the accommodated drug was achieved with modified k-Carrageenan which was comparable with dissolution of the tablet formulation containing other superdisintegrants. The competent concentration of k-Carrageenan was found to be $5-15 \%$ as tablet disintegrant. Modified k-Carrageenan might be encouraging tablet disintegrant in fast dissolving formulations and can be worn in direct compression method.

Keywords: k-Carageenan. Epichlorhydrin. Aceclofenac. Crosslinking. Superdisintegrant

\section{INTRODUCTION}

Therapeutics that has extremely reduced aqueous solubility, the solubility rate is generally the rate limiting pace and therefore exhibits an influence on drug bioavailability 1 . Aceclofenac is non steroidal anti-inflammatory safe drug, which is used in the prevention and treatment of rheumatoid arthritis and osteoarthritis. Aceclofenac belongs to class II drug in biopharmaceutics (BCS) classification i.e. low solubility and high permeability ${ }^{2}$.

The orally administered compressed tablet is the most extensively used solid unit dosage form for delivering therapeutics to patients. Additives play an essential role in the design of the tablet formulation by measuring its activity and ability ${ }^{3}$. Among the tablet additives or excipients, disintegrants are often treated as the most notable as they ensure the disintegration of the dosages form into smaller fragments upon administration, to allow the onset of pharmaceutical dissolution and consequent absorption 4,5.

The general objective of combining one or more disintegrants in the formulation is to enhance the surface area of the dosage form and soften the binding substance and associate together the solid granules that make up the final product. The total effects is that a tablet when disclosed to aqueous media disintegrates first into granules, and then into fine particles ${ }^{6,7}$. The rate of dissolution increases as the particle size reduces and is greatest when the tablets or capsules reduced to fine colloidal particles. Enhanced dissolution increases the rate of absorption of the drug, producing the desired pharmacological action. Various kinds of disintegrant have been identified and used since a long time ${ }^{8}$.

Carrageenans are classified under hydrocolloids sourced from certain red seaweeds, the Rhodophyceae class algae that belong to the genera Hypnea, Eucheuma, Gigartina, Chondrus and Lridaea 9,10. k-Carrageenan is specially procured from the extraction of the Kappaphycus alvarezii tropical seaweed, generally known as Eucheuma cottonii. Modification of kCarrageenan caused swelling property which is an essential parameter for the disintegrant 11 .

The purpose of the present investigation is to explore the feasibility of preparing a modified k-carrageenan and to evaluate its functionality as a superdisintegrants.

\section{MATERIALS AND METHODS}

\section{Materials}

Aceclofenac was procured from Ipca laboratories limited (Mumbai, India). k-Carrageenan was supplied by Mayor Corporation Pvt. Ltd. (Mumbai, India). Epichlorhydrin was procured from Spectrochem (Pvt. Ltd. (Mumbai, India). Croscarmellose Sodium (CCS) was purchased from Signet 
Chemical Corporation Pvt. Ltd. (Mumbai, India) Crosspovidon (CP) was purchased from ISP Technologies Inc. (United States). Sodium starch glycolate (SSG) and Maiz starch (MS) were rocured from Sigma Chemical Co (St. Louis, MO). (Mumbai, India). Dibasic calcium phosphate anhydrous (DCPA), Klucel LF (L-HPC) and Magnesium stearate were supplied from Himedia (Mumbai, India). All other reagents and solvents used were of analytical or HPLC grade.

\section{Methods}

Synthesis and optimization of modified k-Carrageenan by chemical cross-linking

Modified k-Carrageenan was prepared by chemical cross linking method (Table I). Weighed quantity of k-Carrageenan (in varied ratio) was mixed in an alcoholic alkaline solution (KOH $700 \mathrm{~mm}$ and isopropyl alcohol $50 \% \mathrm{v} / \mathrm{v}$ ). The crosslinking agent i.e. epichlorhydrin was added with stirring and left to react for different reaction time (varied in $1 \mathrm{hr}$ and 24 h) and at different temperature (RT to 50-60). After completion of reaction time the product was washed extensively with different solvents like ethanol, cold distilled water and hot $\left(70-80^{\circ} \mathrm{C}\right)$ distilled water ${ }^{12,13}$.
Prepared batches were optimized by swelling degree. In this test $500 \mathrm{mg}$ of powder from each batch was kept in test tube containing distilled water. At the end of $24 \mathrm{~h}$, swelling degree measured in term of increased in volume. To determine the overall swelling features, the swelling index test method is used ${ }^{14}$.

To measure the sample swelling degree of pre-weighed dry samples were immersed in distilled water until maximum swelling was reached. After excessive surface water had been removed with filter paper, the weights of swollen samples were measured. The swelling index was determined by:

Swelling Index (SJ) = [\{Wt - W0 $\} /$ W0 $)] \times 100$

Eq. (1)

Where, $\mathrm{Wt}=$ Mass of wet sample at time $\mathrm{t}$

$\mathrm{W} 0=$ Mass of dry sample at $\mathrm{t}=0$

The swelling behaviours of all optimized formulations that resulted in peak swelling were further researched for swelling index measurement and contrasted with maize starch, crosspovidone (polyplasdone XL), croscarmellose sodium (Ac-Di-Sol), sodium starch glycolate (Primojel), unmodified k-Carrageenan and prepared modified $\mathrm{k}$ Carrageenan swelling index (Table II).

Table I: Preparation of batches of modified k-Carrageenan with different reaction condition

\begin{tabular}{|c|c|c|c|c|c|c|}
\hline $\begin{array}{l}\text { Batch } \\
\text { No. }\end{array}$ & $\begin{array}{l}\text { Ratio of k- } \\
\text { carrageenan } v s \\
\text { epichlorhydrin } \\
(w / w)\end{array}$ & $\begin{array}{l}\text { Washed } \\
\text { with cold } \\
\text { water }\end{array}$ & $\begin{array}{l}\text { Washed } \\
\text { with hot } \\
\text { water }\end{array}$ & $\begin{array}{l}\text { Washed } \\
\text { with } \\
\text { ethanol }\end{array}$ & $\begin{array}{l}\text { Temperature } \\
\left({ }^{\circ} \mathrm{C}\right)\end{array}$ & $\begin{array}{l}\text { Reaction } \\
\text { time (h) }\end{array}$ \\
\hline V1 & $0.6: 1$ & & $\checkmark$ & & $37 \pm 2$ & 1 \\
\hline V2 & & & & $\checkmark$ & & \\
\hline V3 & & & $\checkmark$ & & & 24 \\
\hline V4 & & & & $\checkmark$ & & \\
\hline V5 & $1.5: 1$ & & & & $37 \pm 2$ & 24 \\
\hline V6 & & & & & & \\
\hline V7 & $2: 1$ & & $\checkmark$ & & $37 \pm 2$ & 1 \\
\hline V8 & & & & $\checkmark$ & & \\
\hline v9 & & & $\checkmark$ & & & 24 \\
\hline V10 & & & & $\checkmark$ & & \\
\hline V11 & $3: 1$ & $\checkmark$ & & & $37 \pm 2$ & 1 \\
\hline V12 & & & $\checkmark$ & & & \\
\hline V13 & & & & $\checkmark$ & & \\
\hline V14 & & $\checkmark$ & & & & 24 \\
\hline V15 & & & $\checkmark$ & & & \\
\hline V16 & & & & $\checkmark$ & & \\
\hline V17 & $4: 1$ & & $\checkmark$ & & $37 \pm 2$ & 1 \\
\hline V18 & & & & $\checkmark$ & & \\
\hline V19 & $6: 1$ & & $\checkmark$ & & $37 \pm 2$ & 24 \\
\hline V20 & & & & $\checkmark$ & & \\
\hline V21 & & $\checkmark$ & & & $55 \pm 2$ & 24 \\
\hline V22 & & & $\checkmark$ & & & \\
\hline V23 & & & & $\checkmark$ & & \\
\hline V24 & & $\checkmark$ & & & $37 \pm 2$ & 1 \\
\hline V25 & & & $\checkmark$ & & & \\
\hline V26 & & & & $\checkmark$ & & \\
\hline V27 & $7: 1$ & & $\checkmark$ & & $37 \pm 2$ & 24 \\
\hline V28 & & & & $\checkmark$ & & \\
\hline V29 & 13:1 & & $\checkmark$ & & $37 \pm 2$ & 24 \\
\hline V30 & & & & $\checkmark$ & & \\
\hline
\end{tabular}


Table II: Swelling index measurement and contrasted with maize starch, crosspovidone (polyplasdone XL), croscarmellose sodium (Ac-Di-Sol), sodium starch glycolate (Primojel), unmodified k-Carrageenan and prepared modified k-Carrageenan swelling indices

\begin{tabular}{ll}
\hline Material & $\begin{array}{l}\text { Swelling index } \\
\text { (\%) }\end{array}$ \\
\hline Maize starch & $50 \pm 5$ \\
Crosspovidone (Polyplasdone XL) & $1150 \pm 25$ \\
Croscarmellose sodium (Ac-Di-Sol) & $1490 \pm 28$ \\
Sodium starch glycolate (Primojel) & $1980 \pm 52$ \\
Unmodified k-Carrageenan & $425 \pm 25$ \\
Modified k-Carrageenan & \\
V5 & $2055 \pm 48$ \\
V13 & $2120 \pm 52$ \\
V16 & $1240 \pm 34$ \\
V19 & $1559 \pm 43$ \\
V25 & $1288 \pm 35$ \\
\hline
\end{tabular}

Results are represented as mean $\pm \operatorname{SD}(n=3)$

\section{Evaluation of modified k-Carrageenan}

\section{Particle size distribution}

The speed and force of disintegrating action may depend on the particle size of disintegrants. The size distribution profile of unmodified k-Carrageenan and modified k-Carrageenan was determined by employing Malvern Mastersizer (Mastersizer 2000 version 5.3, Malvern Instruments Ltd. UK) using dry method. Various formulations suitably diluted with distilled water were dropped into the Zetasizer electrophoretic cell for Zeta potential determination.

\section{Aqueous solubility}

Aqueous solubility has been carried out by the measurement of amount of distilled water needed to dissolve $1 \mathrm{gm}$ of the sample. The solution was prepared by heating $\mathrm{k}$ Carrageenan dispersion and modified k-Carrageenan separately in $80^{\circ} \mathrm{C}$ warm water bath.

\section{Viscosity study}

Increased cross linking density reduces polymer viscosity. Transfer $7.5 \mathrm{~g}$ of the dried sample to $600 \mathrm{ml}$ of a beaker and spread in $450 \mathrm{ml}$ of deionized water with agitation for 10 to $20 \mathrm{~min}$. Add enough water to bring the final weight to $500 \mathrm{~g}$ and heat in a continuously agitated water bath until $80^{\circ} \mathrm{C}$ (20-30 $\mathrm{min})$ temperature is reached. Add water in a constant temperature bath at $75^{\circ} \mathrm{C}$ to adjust for loss by evaporation, cool to room temperature $\left(35 \pm 3^{\circ} \mathrm{C}\right)$.

The Brookfield viscometer was used to determine the flow properties of various formulations. Evaluation of the physical stability of systems was carried out by visual inspection of formulations and by performing the rheological measurements. The DVII+ Pro Brookfield Viscometer (Brookfield Engineering Laboratories, Stoughton, MA, United States, with software) with small sample adaptor (spindle and chamber SC4-18/13R) was used to determine flow properties of the various formulations between the percentage torque values of 10 100.

\section{Gel strength study}

Free-radical crosslinking synthetic superabsorbent copolymers and outcomes stated that superabsorbent polymers (SAPs) with elevated water absorption were accompanied by low gel strength and high calculated molecular weight value. The modified and unmodified Formulated k-Carrageenan was placed in the test tube and gelled at $80^{\circ} \mathrm{C}$. The gel resistance measuring device (locally fabricated) was then put on the gel. The time taken by the device to pass through the prepared gel to a depth of $5 \mathrm{~cm}$ for each formulation was evaluated.

\section{IR spectroscopy study}

In determining the degree of substitution, the FT-IR spectra of the modified and unmodified samples was recorded with a Bruker IR spectrophotometer (INVENIO, USA) between 400 and $4000 \mathrm{~cm}^{-1}$. The samples have been evaluated as pellets of potassium bromide (KBr).

\section{Trace analysis of epichlorhydrin}

Toxicology studies indicate that epichlorhydrin has serious toxic impacts on humans 15 , both acute and chronic. The main analytical method available for epichlorohydrin quantification in water includes gas extraction technique 16 .

Standard epichlorhydrin solution was prepared by blending $100 \mathrm{mg}$ of epichlorhydrin in $100 \mathrm{ml}$ of ethanol (1000 PPM). Diluting $5 \mathrm{ml}$ stock solution with $50 \mathrm{ml}$ methylene oxide (100 PPM) was the standard solution. The separating funnel was closed and shaken forcefully to release surplus pressure for $1-2$ min with regular ventilation. After the funnel was still in for $10 \mathrm{ml}$ and extract was gathered for organic layer. Using fresh parts of solvent, extraction was repeated twice. The resulting three extract parts were mixed and the solvent evaporated to near dryness. With $1 \mathrm{ml}$ of methylene chloride, the residue was dissolved and moved to the sample vial for gas chromatography (7890A GC System, Agilent Technologies, US) analysis. Chromatographic conditions are given in Table III.

Table III: Gas chromatography conditions

\begin{tabular}{ll}
\hline Parameters & Specifications \\
\hline Column & Agilent J \& W DB-5ms Ultra inert, $10 \mathrm{~m}^{*} \mathrm{x} 0.18 \mathrm{~mm}, 0.36 \mu \mathrm{m}$ \\
Carrier gas & Helium, Constant flow mode, $1.5 \mathrm{ml} / \mathrm{min}$ \\
Inlet & Pulsed split $24.6 \mathrm{psi}$ at $250 \mathrm{c}$ split $5: 1$ \\
Oven Temperature & $30^{\circ} \mathrm{C}(1 \mathrm{~min}) ; 20^{\circ} \mathrm{C} / \mathrm{min}$ to $100^{\circ} \mathrm{C}(2 \mathrm{~min})$ \\
Detector & $\mathrm{FID}$ at $260^{\circ} \mathrm{C}$ \\
Detector gas & Helium $30 \mathrm{ml} / \mathrm{min}$, air $400 \mathrm{ml} / \mathrm{min}$, makeup (nitrogen) $25 \mathrm{ml} / \mathrm{min}$ \\
Injection size & $4 \mu \mathrm{L}$ \\
\hline
\end{tabular}


Tablet formulation for comparative assessment of the disintegrating impact of modified k-Carrageenan

The aim of the present research was to assess superdisintegrant property of k-Carrageenan in tablet formulation. For comparative assessment of the disintegrating impact of altered k-Carrageenan, different formulations with anhydrous di-calcium phosphate as model water insoluble diluents and having the same concentration of different disintegrating agent were prepared.
Preparation of tablet by direct compression method using model drug: Aceclofenac

Tablets were prepared according to the formula provided in Table IV by direct compression technique using tablet punching machine (Rotary Tablet Machine, Karnavati, India) All components were individually and weighed by 60 mesh sieve. They were blended in geometric proportion and tablets were prepared by direct compression using $8.6 \mathrm{~mm}$ flat round punch sizes using manually operated tablet punching machine.

Table IV: Formula table for Comparative evaluation of disintegrating properties of modified k-Carrageenan in tablet formulation

\begin{tabular}{|c|c|c|c|c|c|c|c|c|c|c|}
\hline \multirow[t]{2}{*}{ Ingredients } & \multicolumn{10}{|c|}{ Batch Code } \\
\hline & $\begin{array}{l}\text { DCPA- } \\
\text { CCS }\end{array}$ & $\begin{array}{l}\text { DCPA- } \\
\text { CP }\end{array}$ & $\begin{array}{l}\text { DCPA- } \\
\text { SSG }\end{array}$ & $\begin{array}{l}\text { DCPA- } \\
\text { MS }\end{array}$ & $\begin{array}{l}\text { DCPA- } \\
\text { UKC }\end{array}$ & $\begin{array}{l}\text { DCPA- } \\
\text { MKC- } \\
\text { V5 }\end{array}$ & $\begin{array}{l}\text { DCPA- } \\
\text { MKC- } \\
\text { V15 }\end{array}$ & $\begin{array}{l}\text { DCPA- } \\
\text { MKC- } \\
\text { V19 }\end{array}$ & $\begin{array}{l}\text { DCPA- } \\
\text { MKC- } \\
\text { V22 }\end{array}$ & $\begin{array}{l}\text { DCPA- } \\
\text { MKC- } \\
\text { V25 }\end{array}$ \\
\hline $\begin{array}{l}\text { Aceclofenac :Class } \\
\text { II drug (mg) }\end{array}$ & 200 & 200 & 200 & 200 & 200 & 200 & 200 & 200 & 200 & 200 \\
\hline $\begin{array}{l}\text { Crosscarmellose } \\
\text { Sodium }\end{array}$ & $5 \%$ & - & - & - & - & - & - & - & - & - \\
\hline (Ac-Di-Sol) & & & & & & & & & & \\
\hline $\begin{array}{l}\text { Crosspovidon } \\
\text { (Polyplasdon XL) }\end{array}$ & - & $5 \%$ & - & - & - & - & - & - & - & - \\
\hline $\begin{array}{l}\text { Sodium starch } \\
\text { glycolate } \\
\text { (Primojel) }\end{array}$ & - & - & $5 \%$ & - & - & - & - & - & - & - \\
\hline Maize starch & - & - & - & $5 \%$ & - & - & - & - & - & - \\
\hline $\begin{array}{l}\text { Unmodified k- } \\
\text { Carageenan }\end{array}$ & - & - & - & - & $5 \%$ & - & - & - & - & - \\
\hline $\begin{array}{l}\text { Modified k- } \\
\text { Carageenan }\end{array}$ & - & - & - & - & - & $5 \%$ & $5 \%$ & $5 \%$ & $5 \%$ & $5 \%$ \\
\hline $\begin{array}{l}\text { Magnesium } \\
\text { stearate }\end{array}$ & $1 \%$ & $1 \%$ & $1 \%$ & $1 \%$ & $1 \%$ & $1 \%$ & $1 \%$ & $1 \%$ & $1 \%$ & $1 \%$ \\
\hline $\begin{array}{l}\text { Dibasic calcium } \\
\text { phosphate } \\
\text { anhydrous (DCPA) }\end{array}$ & q.s. ${ }^{*}$ & q.s.* & q.s.* & q.s.* & q.s.* & q.s.* & q.s.* & q.s.* & q.s.* & q.s. ${ }^{*}$ \\
\hline Total (mg) & 260 & 260 & 260 & 260 & 260 & 260 & 260 & 260 & 260 & 260 \\
\hline
\end{tabular}

*Quantity Sufficient

Determination of effective concentration of modified $k$ carrageenan a disintegrating agent

Tablets with distinct concentrations of altered k-carrageenan (1-15\%) were prepared using Diclofenac as a model drug to determine the efficient concentration of modified kcarrageenan as a disintegrating agent when used in direct compression (Table V).

Table V: Formula of batches prepared by using varied concentration of modified k-Carrageenan

\begin{tabular}{llll}
\hline Ingredients & MKC-1\% & MKC-3\% & MKC-15\% \\
\hline Aceclofenac: Class II drug (mg) & 200 & 200 & 200 \\
Modified k- Carageenan (\%) & 1 & 3 & 15 \\
Magnesium stearate (\%) & 1 & 1 & 1 \\
$\begin{array}{l}\text { Dibasic calcium phosphate } \\
\text { anhydrous (DCPA) }\end{array}$ & q.s. & q.s. & q.s.* \\
Total (mg) & 260 & 260 & 260 \\
\hline *Quantity Sufficient & & &
\end{tabular}


Post compression characterization of aceclofenac tablet formulation

\section{Tablet Thickness}

Micrometer was used for the measurement of thickness of tablet. Ten tablets were taken and their thickness recorded.

\section{Hardness}

Hardness or tablet crushing force implies the force needed to break a tablet in a diametric compression has been determined using the Monsanto tablet hardness tester (Labotech, India).

\section{Friability}

Roche friabilator (Panomex Inc, India) was used to determine the tablet's friability. This machine subjects the tablet to the combined impact of abrasion and shock in a 25 rpm rotating plastic chamber and dropping a tablet in each revolution at a height of 6 inches. Pre-weighted (W1) tablet sample was put in the friabilator and the 100 revolutions were subjected. Tablets were powdered and reweighed after testing (W2). The following formula gives the percentage friability $(\mathrm{F})$ :

$$
F(\%)=W 1-W 2 / W 1 \times 100
$$

Where, $\mathrm{W} 1=$ Weight of tablets before testing

W2 = Weight of tablets after testing.

\section{Disintegration time}

The time of disintegration was evaluated using a disintegration device. The time has been registered for the tablet to totally disintegrate into small particles. Tablet in each tube was introduced with disc and the tube assembly was placed in the beaker containing the disintegration media. The disintegration medium used was phosphate buffer ( $\mathrm{pH}$ 6.8). Time taken for the tablet to disintegrate into small particles was recorded. Disintegration tests for tablets from each batch were conducted in triplicate.

\section{Swelling index of tablets}

A piece of tissue paper folded twice was placed in a small petri dish containing $6 \mathrm{ml}$ of water. A tablet was put on the tissue paper and allowed to completely swell. The swelled tablet was then weighed. Swelling index (SI) can be calculated by following formula:

$$
\text { Swelling index }(\mathrm{SI})=\frac{W a-W b}{W a} \times 100
$$

Wa $=$ Weight of tablet after swelling

$\mathrm{Wb}=$ Weight of tablet before swelling

\section{In-vitro dissolution studies}

The tablets containing model drug (aceclofenac) were subjected to in-vitro dissolution test using the following mentioned technique. The dissolution studies were carried out using USP type II devices, rotated at $75 \mathrm{rpm}$. The dissolution medium used was $900 \mathrm{ml}$ of phosphate buffer ( $\mathrm{pH}$ 6.8). The dissolution medium temperature was maintained at $37 \pm 0.5^{\circ} \mathrm{C}$. At a particular time interval, i.e. 10 , $20,30,40,50,60$ minutes aliquot of the dissolution medium was removed and filtered. The dissolution medium was replaced with same amount of fresh phosphate buffer $\mathrm{cH}$ 6.8) solution to maintain the sink condition. UV spectroscopy (UV visible spectrophotometer, Shimadzu-1800, Japan) verified the absorption of the filtered solution for aceclofenac at $\lambda \max 273.5 \mathrm{~nm}$ and determined the drug content from the standard calibration curve.

\section{Statistical analysis}

Statistical data analysis was done using computer package SPSS version 16 (Chicago, IL). Data are presented as the mean standard deviation (SD).

\section{RESULTS AND DISCUSSION}

\section{Synthesis of modified k-Carrageenan as disintegrant to enhance the solubility}

In chemical crosslinking of k-Carrageenan, the maximum swelling graph was observed in Formula V19 where the ratio of k-Carrageenan was $6: 1$, the reaction time was 24 hours, and hot water $\left(70-80^{\circ} \mathrm{C}\right)$ was used as a solvent for the final product washing. Moderate to significant swelling also observed in formula V5, V15, V22 and V25.

\section{Characterization of modified k-Carrageenan}

\section{Particle size analysis}

Prepared modified k-Carrageenan evaluated for particle size distribution (PSD). PSD of modified k-Carrageenan was compared with PSD results of the unmodified kCarrageenan. It can be seen from Fig. 1 and Fig. 2, the particles of unmodified k-Carrageenan were of narrow range while particles of modified k-Carrageenan were of wide range, which showing modification has been carried out. Larger particle exert more swelling pressure than smaller one as they swell to larger extent which can result in rapid disintegration.

Where,

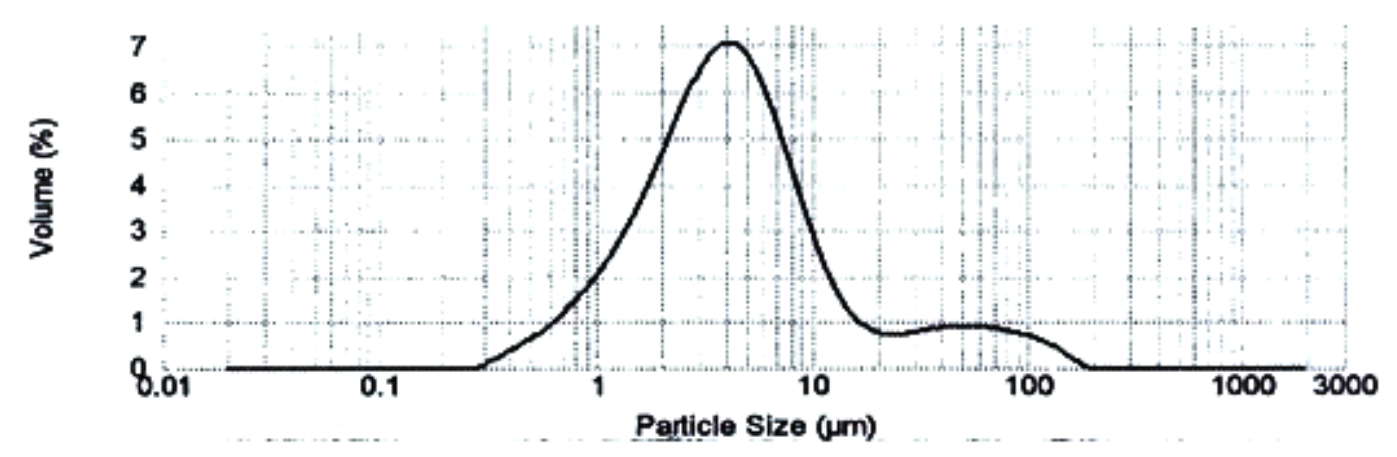

Figure 1: Particle size distribution (PSD) Plot for unmodified k-Carrageenan 


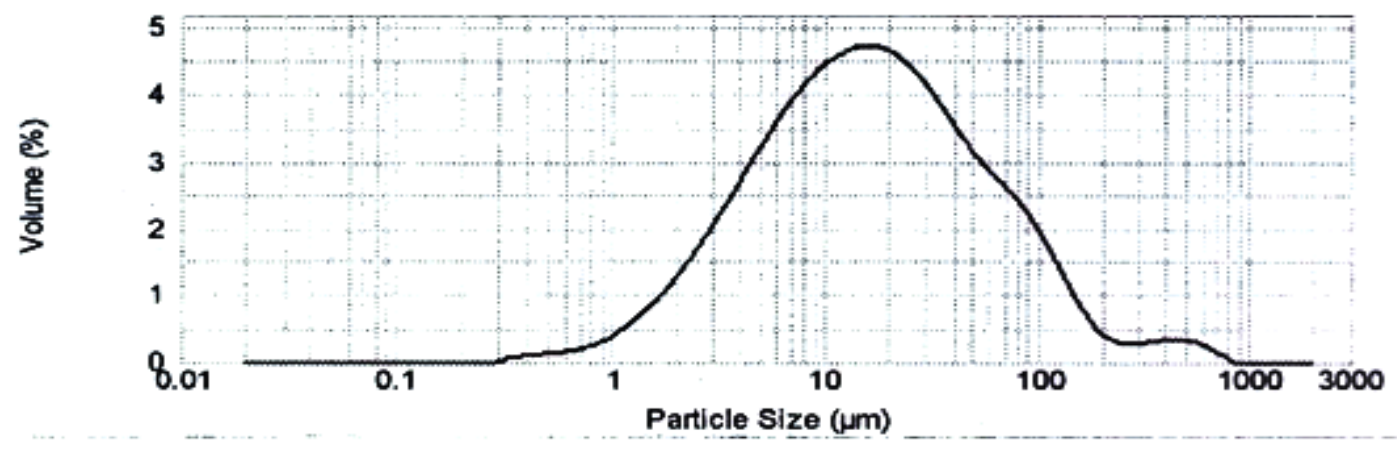

Figure 2: Particle size distribution (PSD) Plot for modified k-Carrageenan

\section{Solubility study}

It can be seen from Table VI that $27 \mathrm{ml}$ water required for the $1 \mathrm{gm}$ of unmodified k-Carrageenan while $39 \mathrm{ml}$ required for solubilizing $1 \mathrm{gm}$ of modified k-Carrageenan indicating solubility of modified form of k-Carrageenan has been reduced due to increased molecular weight because of crosslinking. When a polymer is crosslinked, the entire polymer average molecular weight is boosted, leading in lower solubility. This can therefore be considered as an indication of crosslinking.

Table VI: Results of solubility study

\begin{tabular}{ll}
\hline Polymer & Solubility \\
\hline Unmodified k-Carrageenan & $27 \mathrm{ml}$ for $1 \mathrm{~g}$ \\
Modified k-Carrageenan & $39 \mathrm{ml}$ for $1 \mathrm{~g}$ \\
\hline Results are represented as mean + SD $(n=3)$
\end{tabular}

\section{Viscosity determination}

It can be seen from Table VII that viscosity of unmodified kCarrageenan was 50.5 CPS while viscosity of modified k-
Carrageenan was 48.6 CPS indicating viscosity of modified form of k-carrageenan reduced as crosslinking density decreases viscosity of polymer.

Table VII: Results of viscosity study

\begin{tabular}{llll}
\hline Polymer & $\begin{array}{l}\text { Concentration } \\
(w / v)\end{array}$ & Temperature $\left({ }^{\circ} \mathbf{C}\right)$ & Viscosity (CPS) \\
\hline Unmodified k- Carrageenan & 1.5 & $35 \pm 3$ & $50.5 \pm 5$ \\
Modified k-Carrageenan & 1.5 & $35 \pm 3$ & $48.6 \pm 4$ \\
\hline
\end{tabular}

Results are represented as mean $\pm \operatorname{SD}(n=3)$

\section{Gel strength Study}

It can be seen from Table VIII unmodified k-Carrageenan formed strong gel while modified k-Carrageenan formed weaker gel indicating modified form of k-Carrageenan had crosslinked accompanied by low gel strength.

Table VIII: Results of gel strength study

\begin{tabular}{ll}
\hline Polymer & Gel strength $(\mathrm{Sec})$ \\
\hline Unmodified k-Carrageenan & $65 \pm 5$ \\
Modified k-Carrageenan & $25 \pm 2$ \\
\hline Results are represented as mean \pm SD $(n=3)$
\end{tabular}

\section{IR spectroscopy study}

k-Carrageenan has absorption bands, typical of all polysaccharides, in the 1000 to $1100 \mathrm{~cm}^{-1}$ region. Characteristic absorption bands (Figs. 3 and 4) and intensities are given in Table IX.

Unmodified k-Carrageenan shows peaks at $1234.48 \mathrm{~cm}^{-1}$, $923.93 \mathrm{~cm}^{-1}$ and $846.78 \mathrm{~cm}^{-1}$ indicating ester sulphate, 3, 6anhydrogalactose, Galactose-4-sulphate group respectively.
In addition it also shows peak at $1004.95 \mathrm{~cm}^{-1}$ and $1068.6 \mathrm{~cm}$ 1 which can be due to $\mathrm{C}-\mathrm{H}$ stretching. The IR of modified $\mathrm{k}$ Carrageenan is different from unmodified k-Carrageenan indicating formation of a new product. Reaction of epichlorhydrin with polysaccharide having galactose group generally results in etherification of free hydroxyl group which is indicated by intense peak near $1150 \mathrm{~cm}^{-1}$ in modified k-Carrageenan. 


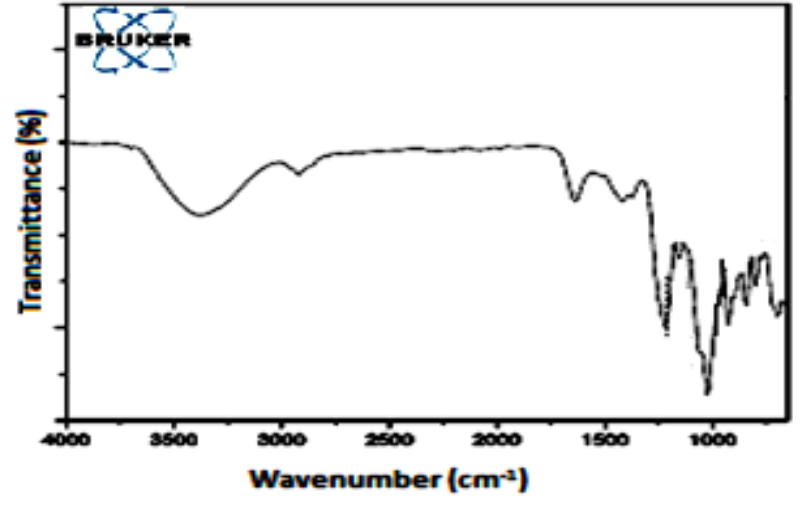

Figure 3: FT-IR Spectrum of unmodified k-Carrageenan. FTIR spectral analysis shows the characteristic absorption bands of polysaccharides in the region of 1000 to $1100 \mathrm{~cm}^{-1}$.

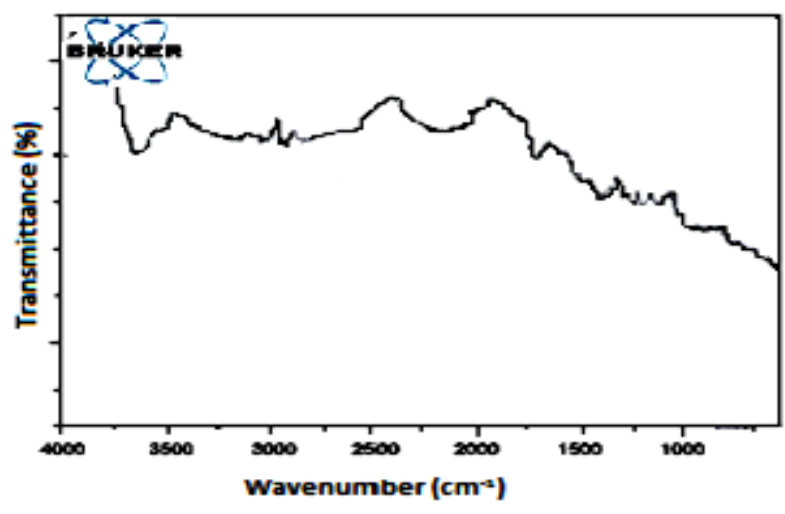

Figure 4: FT-IR Spectrum of modified k-Carrageenan. FT-IR spectral analysis shows the characteristic absorption bands of etherification of free hydroxyl group due to reaction with epichlorhydrin near $1150 \mathrm{~cm}^{-1}$ in modified k-Carrageenan

Table IX: Characteristic absorption bands of unmodified k-carrageenan and modified k-Carrageenan

\begin{tabular}{|c|c|c|c|c|c|}
\hline \multicolumn{2}{|c|}{ Characteristic absorption bands } & \multicolumn{2}{|c|}{ Unmodified k-carrageenan } & \multicolumn{2}{|c|}{ Modified k-carrageenan } \\
\hline Wave number $\left(\mathrm{cm}^{-1}\right)$ & Molecular assignment & Peak & Intensity & Peak & Intensity \\
\hline \multirow[t]{2}{*}{$1220-1260$} & Ester sulphate & 1234.48 & 53.57 & 1203.62 & 61.903 \\
\hline & & & & 1255.70 & 61.902 \\
\hline 918-933 & 3,6-anhydrogalactose & 923.93 & 52.30 & 931.65 & 59.92 \\
\hline $840-850$ & Galactose-4-sulphate & 846.78 & 53.44 & 840.90 & 59.54 \\
\hline 1000-1100 & C-O-C stretch & 1157.33 & 55.85 & 1145.75 & 59.54 \\
\hline
\end{tabular}

\section{Trace analysis of linker}

Chromatograph of sample (modified k-Carrageenan, Batch code: V19) is not showing any peak for epichlorhydrin (Fig.
7) indicating absence of free epichlorhydrin in the product, while comparing with the chromatographs of blank and standard chromatographic solutions (Figs 5 and 6).

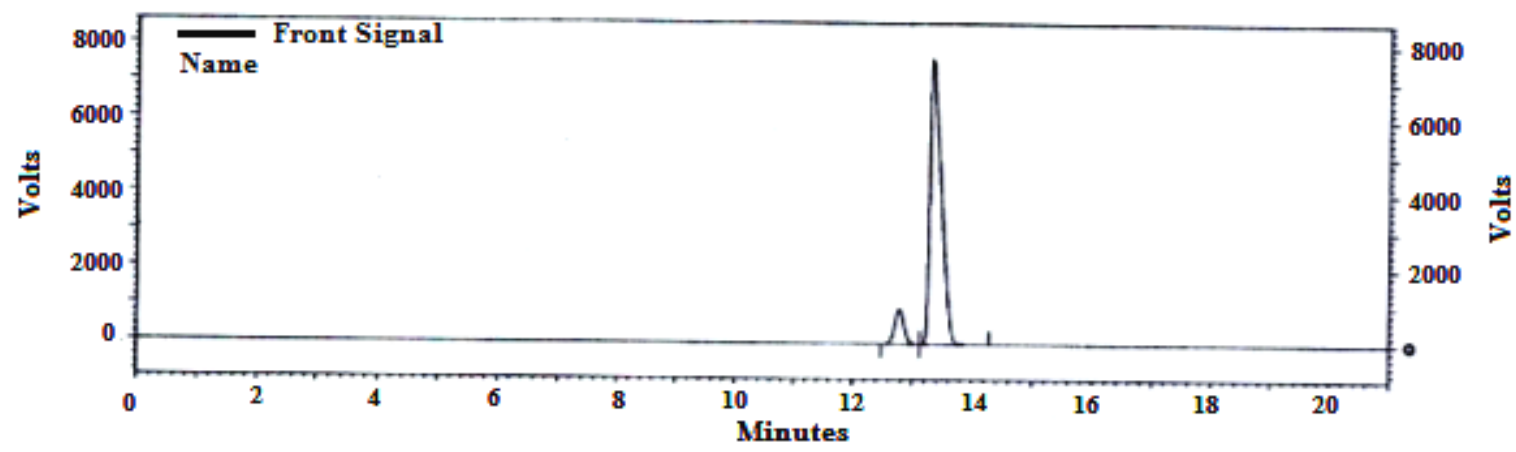

Figure 5: GC Chromatogram of blank solution of dichloromethane (DCM) with Methanol

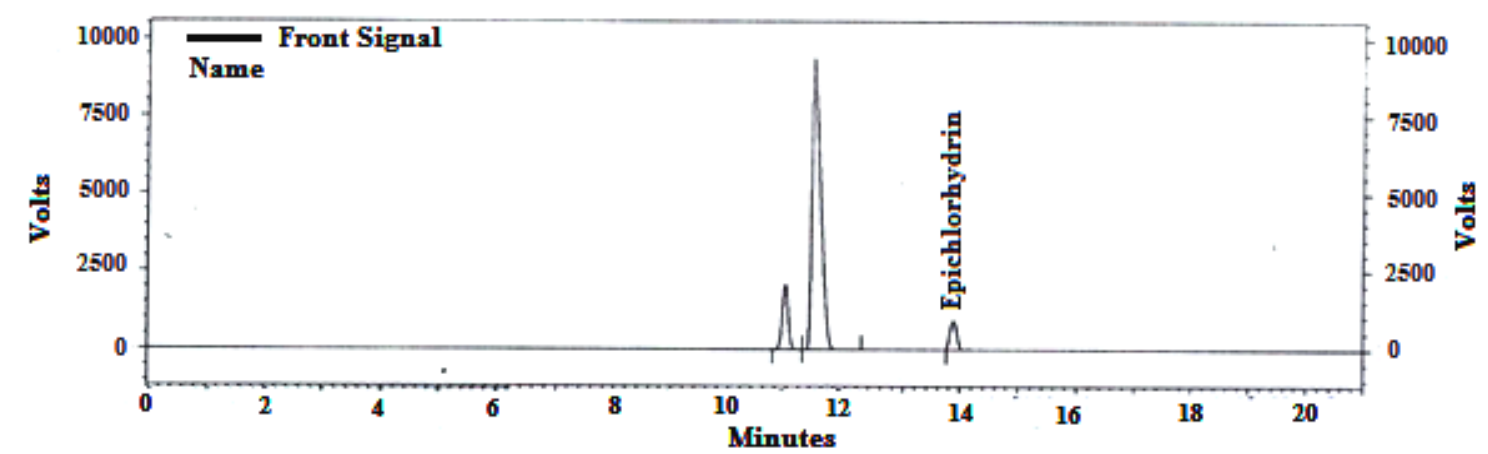

Figure 6: GC Chromatogram of standard solution of epichlorhydrin (crosslinking agent) along with dichloromethane (DCM) and methanol 


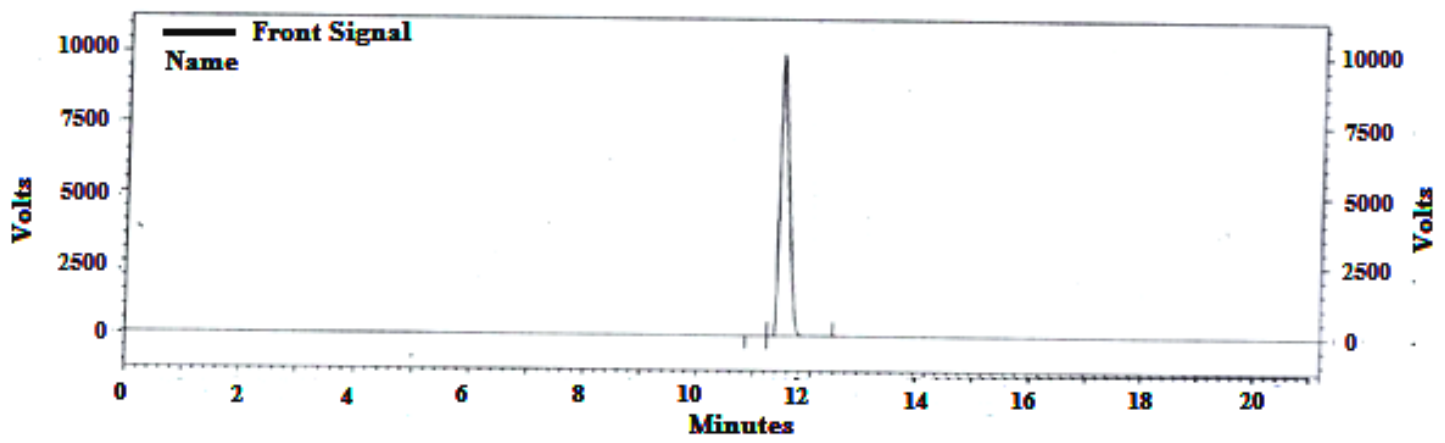

Figure 7: GC Chromatogram of sample: modified k-Carrageenan (Batch V19) along with dichloromethane (DCM)

\section{Post -compression evaluation of aceclofenac tablet}

Formula DCPA-CCS, DCPA-CP, DCPA-SSG tablets were prepared using superdisintegrant and DCPA-MS and DCPAUKC prepared using starch and unmodified k-Carrageenan and formula tablets DCPA-MKC-V5, DCPA-MKC-V15, DCPAMKC-V19, DCPA-MKC-V22, DCPA-MKC-V25 were prepared using modified $\mathrm{k}$-Carrageenan of various batches as disintegrant.

It can be seen from Table $\mathrm{X}$ that disintegration time of tablets prepared using modified k-Carrageenan was comparable with the tablets prepared using superdisintegrants 17,18. Swelling index of tablets of the formulation DCPA-MKC-V19 where modified k-Carrageenan (V19) was used as disintegrant was comparable with the tablets prepared using superdisintegrants.

Results of studies have shown (Table X) that with increasing hardness, disintegration also improves in all formulas prepared with superdisintegrants or altered k-Carrageenan as a disintegrant ${ }^{19}$.

Percentage (\%) cumulative drug release studies have been performed for the following batches i.e. DCPA-CCS, DCPA-CP, DCPA-SSG, DCPA-MS, DCPA-UKC, DCPA-MKC formulation prepared by direct compression in which aceclofenac (class II drug) as a model drug and 5\% disintegrant concentration used. It can be seen from table XI that at the end of $30 \mathrm{~min}$, formulation DCPA-CCS, DCPA-CP, DCPA-SSG containing superdisintegrants (CCS, CP, SSG) shows 55.6\%, 76.6\%, $90.25 \%$ cumulative drug release. DCPA-MS containing traditional disintegrant (Starch) shows $27.75 \%$ cumulative drug release (\% CDR). DCPA-UKC, DCPA-MKC prepared using unmodified k-Carrageenan and modified k-Carrageenan as disintegrant respectively showing $28.87 \%$ and $92.81 \%$ CDR. It can be seen that \% CDR of formulation with modified $\mathrm{k}$ Carrageenan was much higher than formulation with traditional disintegrant and it was comparable with \% CDR of formulation with SSG (Superdisintegrant) 20,21.

Table X: Result of post compression evaluation

\begin{tabular}{llllll}
\hline Batch Code & $\begin{array}{l}\text { Tablet Thickness } \\
(\mathbf{m m})\end{array}$ & $\begin{array}{l}\text { Tablet } \\
\text { Hardness } \mathbf{( K g )}\end{array}$ & Friability (\%) & $\begin{array}{l}\text { Disintegration } \\
\text { Time (S) }\end{array}$ & $\begin{array}{l}\text { Swelling Index } \\
\text { (\%) }\end{array}$ \\
\hline DCPA-CCS & $3.5 \pm 0.14$ & $3.4 \pm 1.0$ & $0.056 \pm 0.03$ & $12 \pm 1.0$ & $182 \pm 08$ \\
DCPA-CP & $3.5 \pm 0.12$ & $3.2 \pm 1.1$ & $0.040 \pm 0.02$ & $11 \pm 1.0$ & $144 \pm 05$ \\
DCPA-SSG & $3.4 \pm 0.15$ & $3.6 \pm 1.1$ & $0.038 \pm 0.02$ & $14 \pm 1.2$ & $258 \pm 15$ \\
DCPA-MS & $3.5 \pm 0.12$ & $3.8 \pm 1.2$ & $0.024 \pm 0.01$ & $24 \pm 1.2$ & $135 \pm 06$ \\
DCPA-UKC & $3.4 \pm 0.14$ & $3.9 \pm 1.2$ & $0.054 \pm 0.02$ & $64 \pm 2.2$ & $105 \pm 05$ \\
DCPA-MKC-V5 & $3.5 \pm 0.12$ & $3.2 \pm 1.4$ & $0.040 \pm 0.02$ & $11 \pm 1.0$ & $185 \pm 08$ \\
DCPA-MKC-V15 & $3.5 \pm 0.13$ & $3.2 \pm 1.5$ & $0.061 \pm 0.04$ & $12 \pm 1.1$ & $260 \pm 10$ \\
DCPA-MKC-V19 & $3.4 \pm 0.11$ & $3.8 \pm 1.5$ & $0.059 \pm 0.03$ & $15 \pm 1.0$ & $125 \pm 04$ \\
DCPA-MKC-V22 & $3.5 \pm 0.14$ & $3.2 \pm 1.1$ & $0.052 \pm 0.02$ & $12 \pm 1.0$ & $166 \pm 06$ \\
DCPA-MKC-V25 & $3.5 \pm 0.14$ & $3.1 \pm 1.2$ & $0.035 \pm 0.01$ & $12 \pm 1.2$ & $145 \pm 05$ \\
\hline
\end{tabular}

Results are represented as mean $\pm \operatorname{SD}(n=3)$

Table XI: Cumulative drug release (\%) of formulation prepared using aceclofenac (class-II) by direct compression

\begin{tabular}{|c|c|c|c|c|c|c|}
\hline \multirow[t]{2}{*}{ Time (min) } & \multicolumn{6}{|c|}{ Cumulative Drug Release (\%) } \\
\hline & DCPA-CCS & DCPA-CP & DCPA-SSG & DCPA-MS & DCPA-UKC & DCPA-MKC \\
\hline 10 & $44.80 \pm 2.2$ & $50.40 \pm 2.8$ & $23.06 \pm 1.8$ & $10.12 \pm 1.2$ & $10.31 \pm 2.0$ & $65.62 \pm 4.2$ \\
\hline 20 & $47.40 \pm 2.4$ & $63.50 \pm 4.1$ & $75.37 \pm 4.9$ & $22.68 \pm 2.1$ & $28.12 \pm 2.5$ & $88.50 \pm 6.8$ \\
\hline 30 & $55.60 \pm 4.2$ & $76.60 \pm 4.5$ & $90.25 \pm 6.1$ & $27.75 \pm 2.2$ & $28.87 \pm 2.4$ & $92.81 \pm 8.8$ \\
\hline 40 & $70.10 \pm 6.1$ & $80.40 \pm 5.2$ & $92.12 \pm 6.5$ & $33.93 \pm 2.4$ & $32.62 \pm 3.2$ & $96.00 \pm 8.4$ \\
\hline 50 & $75.90 \pm 6.5$ & $81.90 \pm 5.8$ & $94.06 \pm 6.6$ & $36.18 \pm 3.1$ & $36.93 \pm 3.6$ & $96.75 \pm 8.4$ \\
\hline 60 & $90.50 \pm 6.8$ & $95.00 \pm 6.1$ & $96.00 \pm 6.2$ & $46.68 \pm 4.8$ & $48.56 \pm 4.8$ & $97.31 \pm 8.9$ \\
\hline
\end{tabular}

Results are represented as mean \pm SD $(n=3)$ 


\section{CONCLUSIONS}

Fast disintegration of tablet is a criterion for ensuring unrestricted conduct in drug dissolution and drug accessibility for bioavailability. Faster drenching of a disintegrating system chaperone by fast protuberance is contemplated as the most coherent necessity for super disintegration. Manipulation in natural polysaccharide are often accomplished to have desired characteristics such as prompt wetting and rapid swelling without the forming of viscous gel that could obstruct dissolution ${ }^{22}$. A small effort was made in the present research to modify k-Carrageenan (marine polysaccharide) by using epichlorhydrin as a crosslinker. Modified k-Carrageenan was analyzed for swelling index, PSD, solubility, viscosity, gel strength, and FTIR after optimizing the system. Modified k-Carrageenan exhibited an index of swelling similar to superdisintegrants such as croscarmellose sodium (CCS), crosspovidone (CP), sodium starch glycolate (SSG) and starch (traditional disintegrant) and contrasted for its disintegrating impact using aceclofenac (BCS Class II) as model drug.

The time of disintegration of tablets prepared with altered kCarrageenan as a disintegrant was similar to that prepared with superdisintegrants. Modified k-Carrageenan as a disintegrant in a tablet formulation resulted in comparatively rapid and higher dissolution of 92.8 percent for cumulative drug release (CDR) of the contained drug at the end of $30 \mathrm{~min}$, which was comparable to the dissolution of superdisintegrant formula.

Thus, it can be concluded that using epichlorhydrin as a crosslinking agent, k-Carrageenan, a marine polysaccharide can be altered by chemical technique. Modified kCarrageenan can be adapted as a disintegrant as it demonstrates the action of disintegration and its impact on the in-vitro dissolution of BCS Class II drug (aceclofenac). The altered k-Carrageenan in tablet formulations has been invented to be a promising superdisintegrant and can be used as an efficient disintegrant in the formulation of fast dissolving tablets in a concentration of 5-15 percent.

\section{Funding}

This research received no external funding.

\section{Conflicts of Interest}

The authors declare no conflict of interest

\section{REFERENCES}

[1] Paarakh, M. P., Jose, P. A., Setty, C., \& Christoper, G. P. Release kinetics-concepts and applications. Int $J$ Pharm Res Tech 2018, 8, 12-20, http://dx.doi.org/10.31838/ijprt/08.01.02.

[2] Magliocca, S., De Caro, C., Lazzarato, L., Russo, R., Rolando, B., Chegaev, K., Cristiano, C. Aceclofenac-Galactose Conjugate: Design, Synthesis, Characterization, and Pharmacological and Toxicological Evaluations. Molecular pharmaceutics 2018, 15, 3101-3110,

https://doi.org/10.1021/acs.molpharmaceut.8b00195.

[3] Shaikh, R., O’Brien, D. P., Croker, D. M., \& Walker, G. M. The development of a pharmaceutical oral solid dosage forms. In Computer Aided Chemical Engineering 2018, 41, 27-65, Elsevier.

[4] Madhulika, G. S. S. V., \& Kuber, B. R. (2019). A review on natural and synthetic polymers employed in the formulation of oral disintegrating tablets. J Drug Deli Therapeutics 2019, 9, 652-658, https://doi.org/10.22270/jddt.v9i2-s.2553.

[5] Ruiz-Picazo, A., Lozoya-Agullo, I., González-Álvarez, I., Bermejo, M., \& González-Álvarez, M. Effect of excipients on oral absorption process according to the different gastrointestinal segments. Expert Opin Drug Deliv 2020, https://doi.org/10.1080/17425247.2020.1813108.
[6] Singh, K., Goyal, L., Bawa, J., Kaur, S., Sharma, S., \& Kumar, D. Fast dissolving tablets: An overview of preparation techniques and evaluation. The Pharma Inno J 2018, 7, 1090-1094.

[7] Acharya, P. C., Shetty, S., Fernandes, C., Suares, D., Maheshwari, R., \& Tekade, R. K. Preformulation in Drug Research and Pharmaceutical Product Development. In Dosage Form Design Considerations 2018 (pp. 1-55). Academic Press.

[8] Arafat, B., Wojsz, M., Isreb, A., Forbes, R. T., Isreb, M., Ahmed, W., \& Alhnan, M. A. Tablet fragmentation without a disintegrant: A novel design approach for accelerating disintegration and drug release from 3D printed cellulosic tablets. Eur J Pharm Sci 2018, 118, 191-199, https://doi.org/10.1016/j.ejps.2018.03.019.

[9] Khalil, H. P. S., Lai, T. K., Tye, Y. Y., Rizal, S., Chong, E. W. N., Yap, S. W., \& Paridah, M. T. A review of extractions of seaweed hydrocolloids: Properties and applications. Express Polym Lett 2018, 12, http://doi.org/10.3144/expresspolymlett.2018.27.

[10] Arufe, S., Torres, M. D., Chenlo, F., \& Moreira, R. Air drying modelling of Mastocarpus stellatus seaweed a source of hybrid carrageenan. Heat Mass Tran 2018, 54, 177-184, https://doi.org/10.1007/s00231-017-2117-1.

[11] Layek, B., \& Mandal, S. Natural polysaccharides for controlled delivery of oral therapeutics: a recent update. Carbohydr Polym 2020, 230 , https://doi.org/10.1016/j.carbpol.2019.115617.

[12] Celebioglu, A., Topuz, F., \& Uyar, T. Water-insoluble hydrophilic electrospun fibrous mat of cyclodextrin-epichlorohydrin polymer as highly effective sorbent. ACS Appl Polym Mater 2018, 1, 54-62, https://doi.org/10.1021/acsapm.8b00034.

[13] Li, L., Zhao, J., Sun, Y., Yu, F., \& Ma, J. Ionically cross-linked sodium alginate/к-carrageenan double-network gel beads with low-swelling, enhanced mechanical properties, and excellent adsorption performance. Chem Eng J 2019, 372, 1091-1103, https://www.x-mol.com/paperRedirect/5670002.

[14] Draksiene, G., Kopustinskiene, D. M., Lazauskas, R., \& Bernatoniene, J. Psyllium (Plantago Ovata Forsk) Husk Powder as a natural superdisintegrant for orodispersible formulations: A study on meloxicam tablets. Molecules 2019, 24, 3255, https://doi.org/10.3390/molecules24183255.

[15] Yalçın, E., Uzun, A., \& Cavuşoğlu, K. In vivo epiclorohidrine toxicity: cytogenetic, biochemical, physiological, and anatomical evidences. Environ Sci Pollut Res 2019,26, 22400-22406, https://doi.org/10.1007/s11356-019-05518-y.

[16] Kumar, C. V., Vasa, P. K., Kumar, Y. R., Aparna, P., \& Pratyusha, P. Enantiomeric Separation of S-Epichlorohydrin and REpichlorohydrin by Capillary Gas Chromatography with FID Detector. Am J Analyt Chem 2016, 7, 772-784, https://doi.org/10.4236/ajac.2016.711069

[17] Bhatti, S., \& Kaushik, M. Utilization of natural superdisintegrant in mouth dissolving tablet: A simplified review. Tablet 2020, 8 , 32-38.

[18] Pacheco-Quito, E. M., Ruiz-Caro, R., \& Veiga, M. D. Carrageenan: Drug Delivery Systems and Other Biomedical Applications. Mar Drugs 2020, 18, 583, https://doi.org/10.3390/md18110583.

[19] Pudjiastuti, P., Wafiroh, S., Hendradi, E., Darmokoesoemo, H., Harsini, M., Fauzi, M. A. R. D., \& Sarker, S. D. Disintegration, In vitro Dissolution, and Drug Release Kinetics Profiles of kCarrageenan-based Nutraceutical Hard-shell Capsules Containing Salicylamide. Open Chem 2020, 18, 226-231, https://doi.org/10.1515/chem-2020-0028.

[20] Sahu, S. K., Banjare, T., Gupta, S., Bhandarkar, A., Sahu, H., Diwedi, S. D., \& Sahu, K. Formulation and evaluation of orodispersible tablet of montelukast sodium. Res J Pharm Technol 2018, 11, 1112-1118, https://doi.org/10.5958/0974360X.2018.00209.3.

[21] Qureshi, D., Nayak, S. K., Maji, S., Kim, D., Banerjee, I., \& Pal, K. Carrageenan: a wonder polymer from marine algae for potential drug delivery applications. Curr Pharm Des 2019, 25, 11721186 , https://doi.org/10.2174/1381612825666190425190754.

[22] Sharma V., Pathak K. Liquisolid system of paclitaxel using modified polysaccharides: In vitro cytotoxicity, apoptosis study, cell cycle analysis, in vitro mitochondrial membrane potential assessment, and pharmacokinetics. Int J Biol Macromol 2019, 137, 20-31, https://doi.org/10.1016/j.ijbiomac.2019.06.188. 